\title{
Differential expression of microRNAs in human parathyroid carcinomas compared with normal parathyroid tissue
}

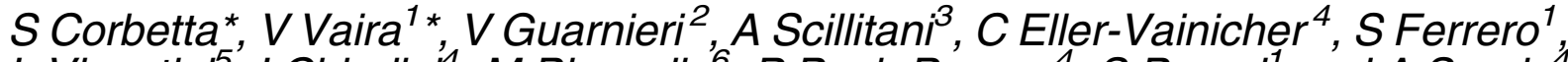

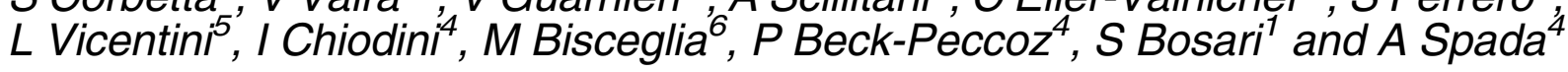

Endocrinology and Diabetology Unit, Department of Medical-Surgical Sciences, Università di Milano, IRCCS Policlinico

San Donato, Via Morandi 30, 20097 San Donato Milanese, Milan, Italy

${ }^{1}$ Pathology Unit, Department of Medicine, Surgery and Dentistry, Università di Milano, A.O.S. Paolo, and IRCCS Fondazione

Ospedale Maggiore Policlinico, Mangiagalli and Regina Elena, Milan, Italy

${ }^{2}$ Unit of Medical Genetics, IRCCS Hospital Casa Sollievo della Sofferenza, San Giovanni Rotondo, Foggia, Italy

${ }^{3}$ Unit of Endocrinology, IRCCS Hospital Casa Sollievo della Sofferenza, San Giovanni Rotondo, Foggia, Italy

${ }^{4}$ Endocrine Unit, Department of Medical Sciences, Università di Milano, IRCCS Fondazione Ospedale Maggiore Policlinico, Regina

Elena, Mangiagalli, Milan, Italy

${ }^{5}$ Endocrine Surgery, IRCCS Fondazione Ospedale Maggiore Policlinico, Regina Elena, Mangiagalli, Milan, Italy

${ }^{6}$ Unit of Pathology, IRCCS Hospital Casa Sollievo della Sofferenza, San Giovanni Rotondo, Foggia, Italy

(Correspondence should be addressed to S Corbetta; Email: sabrina.corbetta@unimi.it)

*(S Corbetta and V Vaira contributed equally to this work)

\begin{abstract}
Parathyroid carcinoma $(\mathrm{PaC})$ is a rare cause of primary hyperparathyroidism. Though the loss of the oncosuppressor CDC73/HRPT2 gene product, parafibromin, has been involved in the hyperparathyroidism-jaw tumor syndrome and in a consistent set of sporadic $\mathrm{PaCs}$, parathyroid carcinogenesis remains obscure. MicroRNAs are a new class of small, non-coding RNAs implicated in development of cancer, since their deregulation can induce aberrant expression of several target genes. The aim of the present study was to identify differentially expressed microRNAs in parathyroid cancers compared with normal tissues. We performed a TaqMan low-density array profiling of four parathyroid cancers harboring $C D C 73$ inactivating mutations and negative for parafibromin immunostaining. Their microRNA profiling was compared with that of two normal parathyroid biopsies. Out of 362 human microRNAs assayed, $279(77 \%)$ were successfully amplified. Fourteen and three microRNAs were significantly down- and over-expressed in parathyroid cancers respectively. Of these, miR-296 and miR-139 were down-regulated, and miR-503 and miR-222 were over-expressed with a null false discovery rate. Carcinomas could be discriminated from parathyroid adenomas by a computed score based on the expression levels of miR-296, miR-222, and miR-503 as miR-139 was similarly down-regulated in both cancers and adenomas. Finally, miR-296 and miR-222 levels negatively correlated with mRNA levels of the hepatocyte growth factor receptor-regulated tyrosine kinase substrate and p27/kip1 levels respectively. These results suggest the existence of an altered microRNA expression pattern in PaCs together with a potential role of miR-296 as novel oncosuppressor gene in these neoplasia.
\end{abstract}

Endocrine-Related Cancer (2010) 17 135-146

\section{Introduction}

Parathyroid carcinoma $(\mathrm{PaC})$ is a rare cause of primary hyperparathyroidism (Marx 2000). It is associated with a poor prognosis, and no curative therapies are available. PaCs occur either sporadically or in family members affected with the hyperparathyroidism-jaw tumor syndrome (OMIM \#145001). Germ-line or somatic inactivating mutations of the oncosuppressor gene CDC73/HRPT2 and loss of heterozygosity at locus $1 \mathrm{q} 25$, resulting in a significant reduction of parafibromin expression, occur in more than $50 \%$ of familial as well as sporadic PaCs (Carpten et al. 2002, 
Howell et al. 2003, Shattuk et al. 2003). Accordingly, parafibromin has been recently proposed as an immunohistochemical marker in the diagnosis of adenomatous and carcinomatous parathyroid lesions (Cetani et al. 2007, Juhlin et al. 2007). Nonetheless, pathogenesis of $\mathrm{PaC}$ is still uncertain and its diagnosis remains a clinical challenge.

MicroRNAs (miRNAs or miRs) are small noncoding RNAs, considered as a class of gene products functioning as negative regulators of gene expression (Croce \& Calin 2005, Schickel et al. 2008). miRs can control gene function through mRNA degradation, translation inhibition or a chromatin-based silencing mechanism (Doench \& Sharp 2004). In humans, about 800 mature miRs have been discovered so far (miRBase, Release 13.0, March 2009; http://miR.sanger.ac.uk/ sequences; Griffiths-Jones et al. 2008). Experimental evidence suggests that miRs may act as either tumor suppressors or oncogenes that control growth and apoptosis (Esquela-Kerscher \& Slack 2006).

The miR expression patterns have been extensively investigated in human cancers, including endocrine tumors, such as thyroid cancers (He et al. 2005, Pallante et al. 2006, Weber et al. 2006, Visone et al. 2007a, Nikiforova et al. 2008). The expression of miRs varies between cancer and normal cells and among different types of cancer. In most cancers investigated so far, the expression of miRs was found to be lower than in the corresponding normal tissue (Calin et al. 2002, 2004a, Takamizawa et al. 2004, Iorio et al. 2005, Lu et al. 2005).

No data about the expression and the role of miRs in $\mathrm{PaCs}$ are currently available. In the present study, the miR expression profiling was first investigated in human PaCs specimens compared to normal parathyroid $(\mathrm{PaN})$ glands. The identified miRs signature associated with the neoplastic feature was further investigated in a subset of sporadic parathyroid adenomas.

\section{Materials and methods}

\section{Patients}

The study investigated four patients with apparently sporadic PaCs. All the patients were affected with primary hyperparathyroidism. Clinical and biochemical data are shown in Table 1. DNA samples were extracted from the peripheral blood and the tumoral specimen of these patients by standard technique and analyzed by direct sequences for CDC73/HRPT2 mutations, as previously described (Guarnieri et al. 2006). Three patients harbored a germ-line $C D C 73$ mutation, while one had a somatic

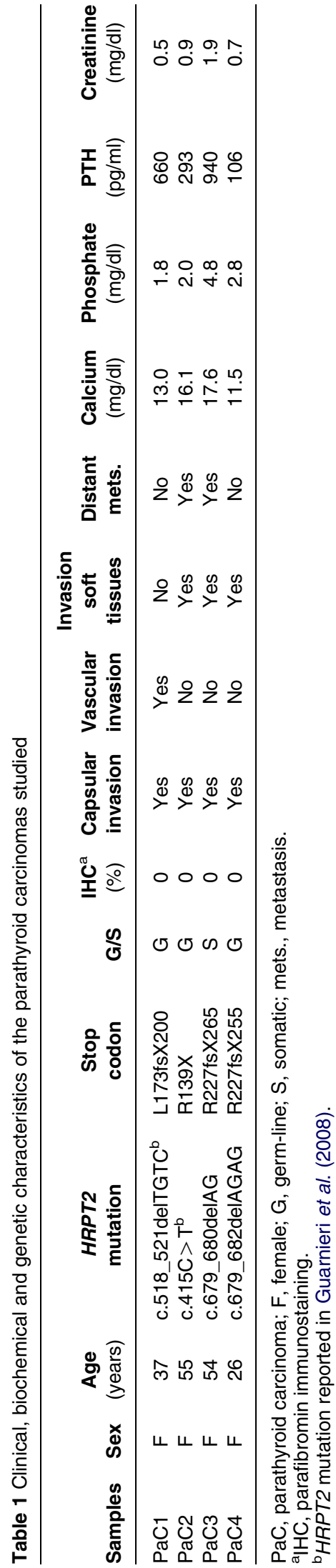


mutation in the DNA from the parathyroid cancer (Table 1). All the mutations were confirmed on two independent DNA sample extractions and generated premature stop codons (Table 1), which are predicted to cause truncated proteins of different sizes.

The study enrolled three female patients with $\mathrm{PaN}$ function, who had one parathyroid gland incidentally removed during surgery because of thyroid disease. Two were profiled and the other one was enrolled for validation assays. Additional 26 patients affected with sporadic primary hyperparathyroidism (17 females, 9 males; age at presentation $56.5 \pm 10.5(30-75)$ years; plasma ionized calcium $1.59 \pm 0.22$ (1.35-2.20) $\mathrm{mmol} / \mathrm{l}$; serum calcium 11.6 $\pm 1.1(10.2-15.4) \mathrm{mg} / \mathrm{dl}$; serum phosphate $2.4 \pm 0.3(1.6-2.9) \mathrm{mg} / \mathrm{dl}$; serum parathyroid hormone (PTH) 300.6 293.0 (66-1180) $\mathrm{pg} / \mathrm{ml}$; mean \pm s.D. (range)) were included for the analysis of the significant varied miRs.

In all the patients, fasting serum total calcium, phosphate, and creatinine were measured by a multichannel autoanalyzer. Serum ionized calcium was measured by an ion-selective electrode (AVL LIST GmbH Medizintechnik, Graz, Austria). Intact PTH was determined by a chemiluminescent immunoassay (Nichols Advantage, Nichols Institute Diagnostics, San Clemente, CA, USA).

The study was approved by the Institutional Review Board of the Ospedale Casa Sollievo della Sofferenza in San Giovanni Rotondo (FG), and all the patients gave their informed consent.

\section{Parathyroid tissue samples}

For molecular investigation, small fresh samples from tumor tissues (4 PaCs and 26 parathyroid adenomas) and $\mathrm{PaN}$ glands were obtained at surgery, snap-frozen in liquid nitrogen and stored at $-80^{\circ} \mathrm{C}$. Specimens from $\mathrm{PaCs}$ were sampled from the central portion of the tumors to avoid the contamination of parathyroid tissue with adjacent non-parathyroid tissue. Histologic classification for PaCs was established according to WHO published guidelines (Bondenson et al. 2004). Informations on the PaCs specimens are shown in Table 1.

All carcinoma samples were analyzed by immunohistochemistry (IHC) for the parafibromin expression. The excised cancers were fixed in $10 \%$ buffered formalin followed by conventional processing and embedded in paraffin. Four-micrometre-thick sections were cut and stained with hematoxylin and eosin for histopathological assessment. IHC was performed on paraffin-embedded tissues. For this purpose, heatinduced antigenic retrieval for detection of parafibromin was performed on deparaffinized $4 \mu \mathrm{m}$ sections that were incubated for 3 cycles of $15 \mathrm{~min}$ in $10 \mathrm{mM}$ citrate buffer ( $\mathrm{pH}$ 6.0) using a $360 \mathrm{~W}$ microwave oven. Tissue sections were then incubated with a primary monoclonal antibody to parafibromin (1:200 dilution; clone sc-33638, Santa Cruz Biotechnology Inc, Santa Cruz, CA, USA), raised against the C-terminal portion (amino acid 87-100) of the molecule. Immunostaining was performed using an Envision Kit on a Dako automatic stainer (Dako, Carpinteria, CA, USA). PaNs and endothelial/stromal cells dispersed throughout the carcinoma parenchyma were included as external and internal positive controls (Gill et al. 2006). Negative controls included omission of the primary antibody from the staining of tumor sections. Slides were counterstained with hematoxylin, dehydrated, and mounted. The stained sections from all the cases were examined by a pathologist (M B). The absence or presence of nuclear immunoreactivity was recorded as negative or positive respectively (Table 1). Tumors were scored as negative when no tumor cells showed a specific nuclear staining.

\section{miR-enriched and total RNA extraction procedures}

miR-enriched RNA for low-density array analysis was isolated from frozen tissues of four $\mathrm{PaCs}$ as well as from two PaN specimens using mirVana miRNA Isolation Kit (Ambion Inc., Austin, TX, USA) according to manufacturer protocol. Total RNA from 26 parathyroid adenomas, 4 carcinomas, and $3 \mathrm{PaN}$ specimens was purified with TRIzol reagent (Invitrogen) according to manufacturer instruction. Following extraction, miR-enriched RNA and total RNA were quantified spectrophotometrically.

\section{Reverse transcription reactions}

Reverse transcription (RT) reactions for low-density array analysis were performed in a multiplex modality, with up to 48 different primers pooled per mix (Multiplex RT for TaqMan miR Assay, Human Pool set, P/N 4384791). Eight different multiplex RTs were then performed for all the samples. In all RT mix, two reference small nuclear RNAs (snoRNA 44 and 48) were constantly included to standardize retrotranscription efficiencies between different reactions. In each mix, $100 \mathrm{ng}$ miR-enriched RNA were reverse transcribed using TaqMan miR RT Kit in a final volume of $10 \mu \mathrm{l}$, following manufacturer instructions. Samples were incubated at $4{ }^{\circ} \mathrm{C}$ for $5 \mathrm{~min}$, then at $16^{\circ} \mathrm{C}$ for $30 \mathrm{~min}, 42^{\circ} \mathrm{C}$ for $30 \mathrm{~min}$, and $85^{\circ} \mathrm{C}$ for $5 \mathrm{~min}$.

Single miRs and mRNA expression analyses were performed on the samples analyzed by low-density 
arrays and additional 26 parathyroid adenomas and 1 PaN sample using total RNA as source. For single miR-RT-PCRs, $100 \mathrm{ng}$ total RNA were reverse transcribed for RNU48, miR-296, miR-139, miR-222, and miR-503 using $1 \mu \mathrm{l}$ target specific primers and TaqMan miR RT Kit in a final volume of $15 \mu \mathrm{l}$. Samples were incubated in thermal cyclers as described above. For target mRNAs detection, $200 \mathrm{ng}$ total RNA from each samples (23 adenomas, 4 carcinomas, and 3 normal specimens) were retrotranscribed through the HighCapacity cDNA Archive Kit in a final volume of $100 \mu \mathrm{l}$ at the following conditions: $25^{\circ} \mathrm{C}$ for $10 \mathrm{~min}, 37^{\circ} \mathrm{C}$ for $120 \mathrm{~min}$, and $85^{\circ} \mathrm{C}$ for $5 \mathrm{~min}$.

All reagents, multiplex primers, kit, and instruments were from Applied Biosystems (Forster City, CA, USA).

\section{TaqMan low-density array-human MicroRNA v1.0 panel (early access)}

The eight RT-reaction mix for each sample were diluted 62.5-fold in nuclease-free water before being loaded on the micro fluidic (MCF) card. Three hundred and sixtytwo miRs as well as one of the three reference small nuclear RNAs (U6b) were analyzed in duplicate (two arrays per sample) by MCF method based on TaqMan technology. The other two reference snoRNAs (sno44 and sno48) were amplified eight times each per card (total times $=16$ ), corresponding to the eight different RT reactions. Each of the eight RT mix was loaded in a preconfigured fill port of the MCF card following manufacturer instructions. Briefly, $50 \mu \mathrm{l}$ of cDNA along with $2 \times$ TaqMan Universal Master mix (1:1 $\mathrm{v} / \mathrm{v}$ ) were dispensed per port of the low-density array. The cards were then centrifuged, sealed and run on ABI Prism 7900HT Sequence Detection System. The average and the standard deviation of RNU 44 and 48 amplification values (threshold cycles, $C_{\mathrm{t}} \mathrm{s}$ ) were calculated among the different ports of a single array, and the results of the two arrays were compared. As expected, the amplification data were the same in all different reaction mix in each sample (Supplementary Table 1, see section on supplementary data given at the end of this article). In addition, the amplification values of snoRNAs were constant in all the array's ports as well as between the two different arrays per sample $(P>0.05$, ANOVA adjusted for multiple testing using the Bonferroni method).

For each sample run on miR array, instrument raw data were converted in $C_{\mathrm{t}}$ values by SDS 2.1 software. All reagents, instruments, and software were from Applied Biosystems.
$C_{\mathrm{t}}$ were then transformed in miRs relative quantities (RQs) using the geometrical average of the three snoRNAs as normalization factor. For all expressed miRs, we calculated fold change ratios (FC) between tumoral and PaN specimens on median normalized RQs. As threshold for significant different expression, we set $\mathrm{FC}=5.0$ or 0.2 , for over- or under-expression respectively. We chose to use stringent conditions for significant inclusion criteria of miRs based on our previous experience on miR analysis and to gain higher results reproducibility (unpublished observations).

\section{Single real-time RT-PCR}

Single miRs and mRNA expression analyses were performed on $4 \mathrm{PaCs}, 26$ parathyroid adenomas, and 3 PaN samples. For single miR expression evaluation, $15 \mathrm{ng}$ cDNA of each sample were amplified with specific primers and probes for RNU48 and the miR-296, miR-139, miR-222, and miR-503 (assay numbers are listed in Supplementary Table 2, see section on supplementary data given at the end of this article). miRs expression relative to RNU48 was calculated using the $2^{-\Delta \Delta C_{t}}$ formula (User Bulletin 2, Applied Biosystems) and the average of PaNs values as calibrator $(1 \times$ sample $)$.

We investigated the gene expression of some putative targets of identified miRs in our series of parathyroid samples. The hepatocyte growth factor-regulated tyrosine kinase substrate (HGS), p27/Kip1, and cyclin D1 mRNAs were relatively quantified by qPCR besides two housekeeping genes ( $\beta$-actin and HPRT1). Specific primers and probes were commercially available as gene expression assays and are as follows: HGSHs00610371_ml, p27/Kip1-Hs00153277_m1, cyclin D1-Hs00277039_m1, $\beta$-actin-Hs99999903_ml, and HPRT1-Hs99999909_ml. For each target mRNA quantification, $8 \mathrm{ng}$ cDNA were amplified using $0.5 \mu \mathrm{l}$ of assay numbers in a final volume of $10 \mu \mathrm{l}$. All the samples were analyzed in duplicate, and the geometrical mean of the two reference genes was used as normalization factor for target RQ in all the samples. All reagents and instruments were from Applied Biosystems.

\section{Immunohistochemistry of putative miR targets}

We investigated HGS, p27/Kip1, and cyclin D1 protein expression in the $3 \mathrm{PaN}$ glands, 26 adenomas, and 4 $\mathrm{PaCs}$ by IHC on representative formalin-fixed paraffinembedded (FFPE) tissue blocks. Briefly, $4 \mu \mathrm{m}$-thick sections cut from FFPE blocks were stained $1 \mathrm{~h}$ at room temperature with mouse monoclonal primary 
antibodies for HGS (1:400, Alexis Biochemicals, San Diego, CA, USA), p27/Kip1 (1:1000, DakoCytomation, Milan, Italy), and cyclin D1 (1:30, Thermo Fisher Scientific, Freemont, CA, USA). For antigen retrieval, slides were microwaved for $35 \mathrm{~min}$ in EDTA solution. IHC was performed using a Dako instrument (Dako), and immunostaining was revealed by Dako EnVision Detection Kit with Peroxidase/ diaminobenzidene (DAB) as chromogen. All the slides were counterstained with hematoxylin.

Two authors (S F and S B) independently evaluated immunoreactivity. Cyclin D1 and p27/Kip1 immunostaining was evaluated at nuclear level, whereas HGS immunoreactivity was cytoplasmatic. Specific immunoreactivities were graded 0-3: 0 , absence of immunoreactivity; $1,<10 \% ; 2,10-50 \%$; and 3 , more than $50 \%$ in at least 400 cells in the main representative high-power field.

\section{Statistical analysis}

Variations in miR expression profiles among patients were investigated by different efforts. miR RQs were median centered and $\log 2$ transformed. For unsupervised hierarchical clustering, the 1-Rank correlation was employed as similarity metric, and the centroid was chosen as linkage method (dChip software, DNA-Chip Analyzer 2006, www.dChip.org).

Univariate analysis was used for group comparison on $\log 2$-transformed RQ (Welch $t$ test, GraphPad Prism 4 software); $P$ values $<0.05$ were considered significant. Samples were also analyzed by significant analysis of microarray (SAM, two-class unpaired $T$-statistic; www-stat.standford.edu/ tibs/SAM/) for difference among groups and false discovery computing rate (FDR), and by BRB-Array Tool (http://linus.nci.nih. gov/BRB-ArrayTools) version 3.7 (Biometrics Research Branch, NCI, Bethesda, MD, USA) for class prediction and supervised sample gathering. Due to the limited sample size, the featured selection criteria for a miR to be included in the class prediction classifier were a different expression between the two classes (normal and tumoral parathyroid samples) of at least twofold and at 0.05 significance level. To compute the misclassification rate, the leave-one-out cross-validation method (1000 random permutations) was used. Class comparison function of BRB-Array Tool (two-sample $t$-test with random variance model) was used to find the genes that discriminate among classes with a maximum allowed proportion of false positive genes of 0.1 and a confidence level of FDR assessment of $80 \%$.

The analysis of miR predicted targets was done using four algorithms: TargetScan 4.2 (www.targetscan.org),
PicTar (http://pictar.bio.nyu.edu), miRanda (http:// cbio.mskcc.org/cgi-bin/mirnaviewer/mirnaviewer.pl), and miRBase Targets (http://microrna.sanger.ac.uk/ targets/v5).

When the expression of miR-296, miR-139, miR222, miR-503, and HGS was evaluated in parathyroid adenomatous and carcinomatous samples, Student's $t$-test was used to investigate for significant differences between the two groups on $\log 2$-transformed RQs (GraphPad Prism 4 software). FC ratios were calculated for each miRs between averaged RQs of adenomas and carcinomas samples with respect to PaN samples. A global score of the three miRs (miR296, miR-222, and miR-503) for each sample was performed multiplying RQs as follows:

$$
\begin{aligned}
\operatorname{miR} \text { score }= & \operatorname{miR} 222-\mathrm{RQ} \times \operatorname{miR} 503-\mathrm{RQ} \\
& \times(1 / \mathrm{miR} 296-\mathrm{RQ})
\end{aligned}
$$

To assess a correlation between miR-296 and HGS mRNA expression levels, the Spearman non-parametric method was used (GraphPad Prism 4 software). A $P$ value of $<0.05$ was considered significant.

\section{Results}

\section{miR expression signature in $\mathrm{PaCs}$ and normal samples}

We analyzed miR expression profile in two $\mathrm{PaN}$ samples as well as in four PaCs. Among the 362 target miRs, $279(77 \%)$ were successfully amplified in at least one group of specimen (either normal or neoplastic samples, Supplementary Table 2). The remaining 83 transcripts were undetected $\left(C_{\mathrm{t}}>40\right)$ in the whole sample dataset (Supplementary data).

Unsupervised hierarchical cluster was able to correctly separate the two normal specimens from the tumors (data not shown). At the selected cutoff $(\mathrm{FC}<0.2$ and $>5$ ), $57 \mathrm{miRs}$ resulted differentially expressed, 25 and 32 miRs resulting over- and downexpressed in tumors compared with PaNs respectively (Supplementary Table 2). At univariate analysis ( $t$ statistic), 14 down-expressed miRs out of 32 had a significant $P$ value $(P<0.05)$, whereas in the overexpressed set 3 miRs displayed a statistically significant difference (miR-222, miR-503, and miR-517c; Fig. 1 and Supplementary Table 2). For FDR computing and differentially modulated miR validation in parathyroid neoplasms, we performed SAM analysis. Four of the previously identified miRs had a null FDR $(q$-value $=0)$, with miR-296 and miR-139 being 

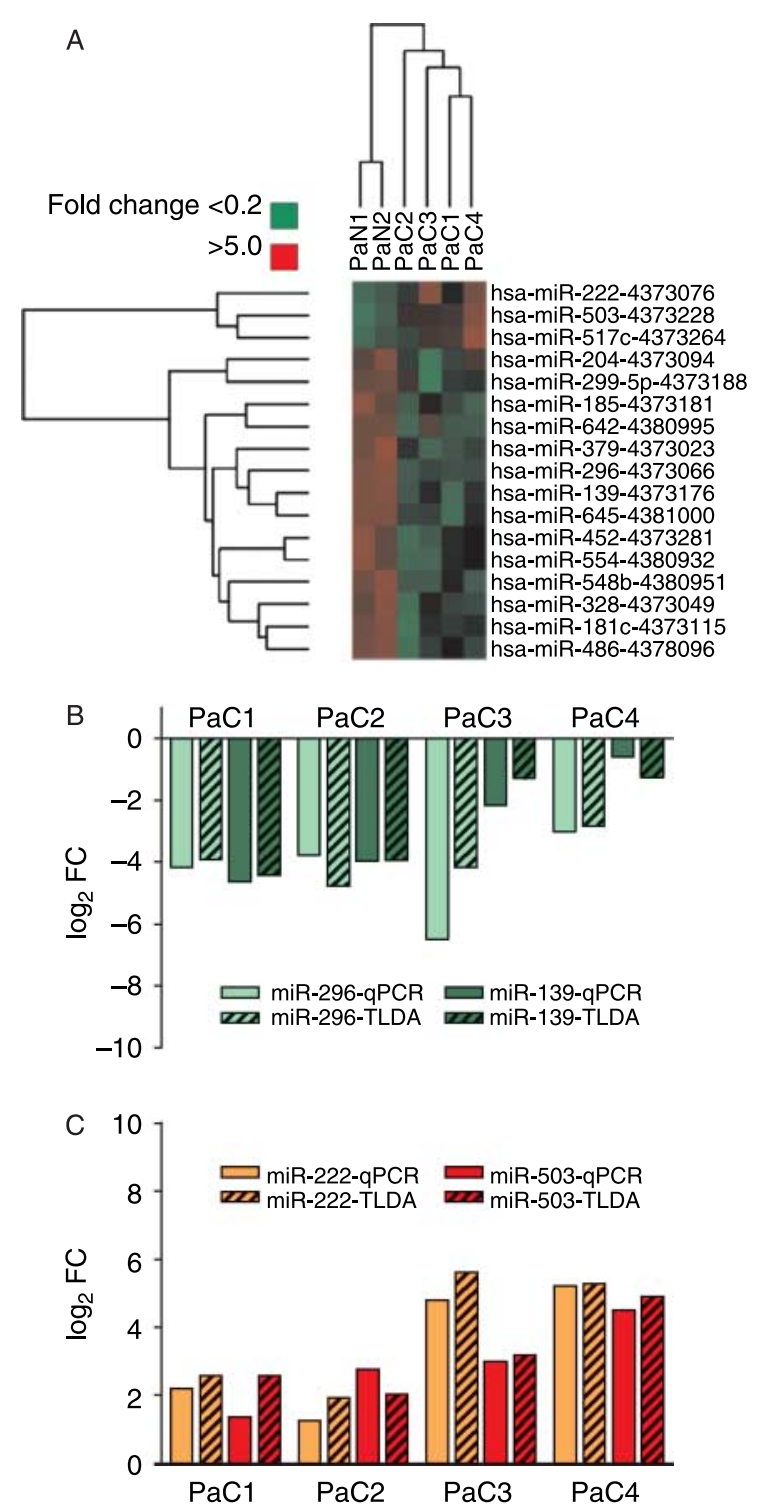

Figure $1(A)$ miR expression signature discriminated parathyroid carcinomas $(\mathrm{PaC})$ from normal samples $(\mathrm{PaN})$. Hierarchical clustering with significantly different expressed miRs $(n=17)$ distinguishes normal specimens from parathyroid carcinomas (red dots, over-expressed miRs; green dots, under-expressed miRs). miR assay numbers are displayed horizontally, and samples are listed vertically. (B and C) Validation by single qPCRs of miRs differentially expressed in parathyroid carcinomas compared with normal samples with a null FDR. Relative quantities of miR-296 and miR-139 (B) and of miR-222 and miR-503 (C) are shown for LDA data (striped colors bars) and single qPCRs (solid colors bars).

down-expressed, and miR-503 and miR-222 being up-regulated in PaCs. The differential expression of miR-139, miR-296, miR-222, and miR-503 between $\mathrm{PaCs}$ and normal samples was validated by single qPCR (Fig. 1, panels $\mathrm{B}$ and $\mathrm{C}$ for the under- and over-expressed miRs respectively).

\section{Supervised sample classification with class prediction analysis}

To clarify which miR could selectively distinguish $\mathrm{PaN}$ specimens from carcinomas, we performed class prediction analysis. Twenty-seven miRs were enrolled in the classifier, 15 of which were previously identified by univariate analysis (Table 2). The two predictor models, compound covariate predictor and the diagonal linear discriminant analysis, were able to categorize all the samples in the appropriate class with a sensitivity and specificity of $100 \%$. The performance of the classifier was tested on hierarchical clustering ability to separate the two sample groups (data not shown). Importantly, the ability of miR-296 to distinguish normal from cancer parathyroid samples was confirmed by class comparison test $(P=0.00127$, data not shown).

Table 2 Class prediction analysis: miRs included in the classifier are listed

\begin{tabular}{|c|c|c|c|c|}
\hline miR & $\begin{array}{l}\text { Chromos- } \\
\text { ome map }\end{array}$ & $\begin{array}{c}\mathrm{FC} \mathrm{PaCl} \\
\mathrm{PaN}\end{array}$ & $\begin{array}{c}\text { Parametric } \\
P \text { value }^{\mathrm{a}}\end{array}$ & $\begin{array}{c}\text { Percentage } \\
\text { of CV } \\
\text { support }^{b}\end{array}$ \\
\hline miR-296 & $20 q 13.32$ & 0.028 & 0.0012 & 100 \\
\hline miR-486 & $8 p 11.21$ & 0.032 & 0.0027 & 100 \\
\hline miR-656 & $14 q 32.31$ & 0.02 & 0.0038 & 83 \\
\hline miR-185 & $22 q 11.2$ & 0.043 & 0.0054 & 83 \\
\hline miR-139 & $11 q 13.4$ & 0.068 & 0.008 & 100 \\
\hline miR-452 & Xq28 & 0.05 & 0.0081 & 83 \\
\hline miR-601 & $9 q 33.3$ & 0.049 & 0.009 & 83 \\
\hline miR-575 & $4 q 21.22$ & 0.04 & 0.013 & 83 \\
\hline miR-661 & $8 q 24.3$ & 0.07 & 0.016 & 83 \\
\hline miR-548b & $6 q 22.31$ & 0.103 & 0.019 & 83 \\
\hline miR-379 & $14 q 32.31$ & 0.1 & 0.02 & 83 \\
\hline miR-639 & $19 p 13.12$ & 0.029 & 0.022 & 67 \\
\hline miR-328 & $16 q 22.1$ & 0.112 & 0.027 & 67 \\
\hline miR-204 & $9 q 21.11$ & 0.117 & 0.028 & 50 \\
\hline miR-554 & $1 q 21.3$ & 0.119 & 0.029 & 33 \\
\hline miR-566 & $3 p 21.31$ & 0.038 & 0.030 & 50 \\
\hline miR-381 & $14 q 32.31$ & 0.08 & 0.034 & 50 \\
\hline miR-299-5p & $14 q 32.31$ & 0.134 & 0.034 & 50 \\
\hline miR-642 & $19 q 13.32$ & 0.195 & 0.037 & 17 \\
\hline miR-369-5p & $14 q 32.3$ & 0.25 & 0.039 & 17 \\
\hline miR-548d & $8 q 24.13$ & 0.09 & 0.039 & 50 \\
\hline miR-181c & $19 q 13.12$ & 0.146 & 0.04 & 33 \\
\hline miR-504 & Xq26.3 & 0.45 & 0.045 & 17 \\
\hline miR-627 & $15 q 15.1$ & 0.15 & 0.046 & 33 \\
\hline miR-555 & $1 q 22$ & 0.1 & 0.049 & 17 \\
\hline miR-503 & Xq26.3 & 8.984 & 0.031 & 50 \\
\hline $\mathrm{miR}-517 \mathrm{c}$ & $19 q 13.41$ & 117.052 & 0.02 & 83 \\
\hline
\end{tabular}

$\mathrm{PaC}$, parathyroid carcinoma; PaN, normal parathyroid.

${ }^{a}$ Refers to the $t$-statistic value obtained separately for each gene when the two samples classes were compared (BRB software). ${ }^{\mathrm{b}}$ Percent cross-validation support: a percent of samples such that the gene remains significant even if the samples are removed from the analysis. Thus, this value characterizes number of times when this gene is used for sample classification in the leave-one-out cross-validation procedure. 

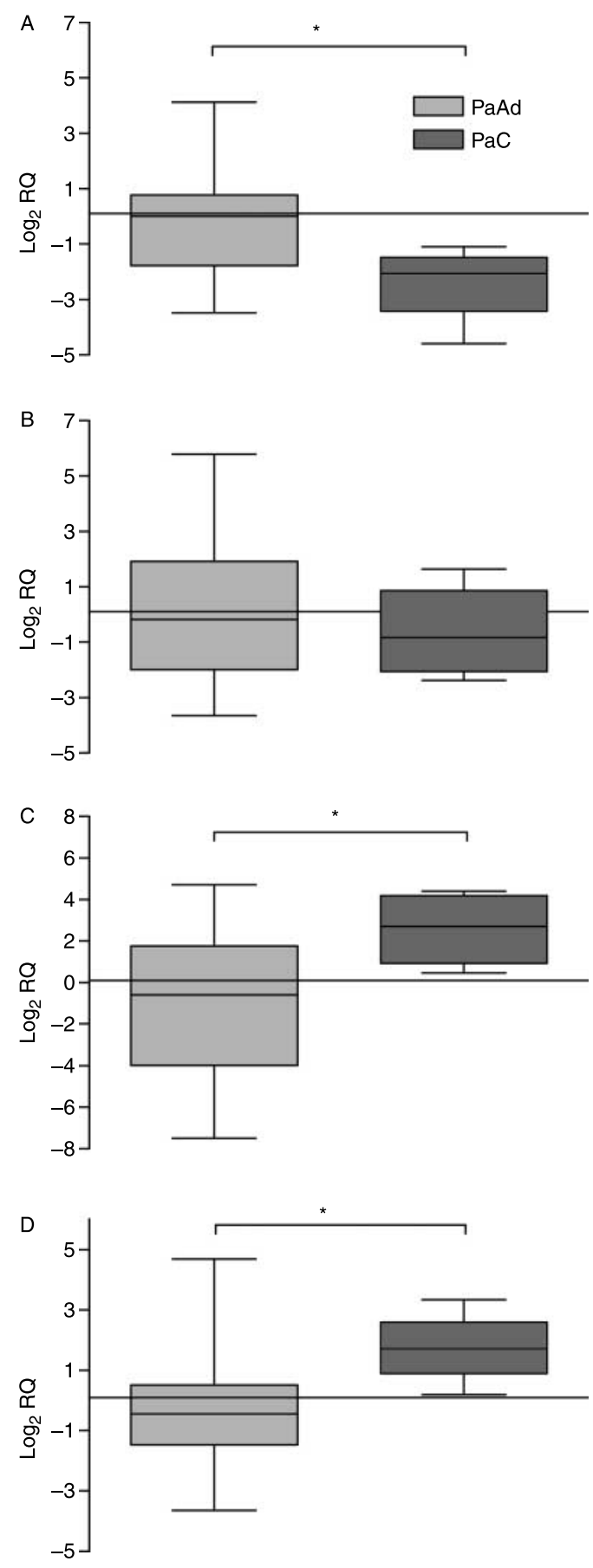

Figure 2 Significant varied miRs expression levels analysis in parathyroid adenomas (PaAd). The expression of miR-296, miR-139, miR-222, and miR-503 was evaluated in 26 parathyroid adenomas and in the 4 carcinomas. miRs levels in parathyroid lesions are relative to three normal controls, and the logarithmic scale was used to better visualize over- or under-expression. The cancer-specific miR expression could be verified for miR-296 (A), miR-222 (C), and miR-503 (D). miR-139 (B) was not differentially expressed between the two groups of disease. ${ }^{*} P<0.05$.
miR-296, miR-139, miR-222, and miR-503 expression levels in sporadic parathyroid adenomas

By single real-time RT-PCRs, the expression of the two significantly under-expressed miR-296 and miR-139 and of the two over-expressed miR-222 and miR-503 identified in PaCs was investigated in $4 \mathrm{PaCs}$ and 26 parathyroid sporadic adenomas, using the average of three PaN tissues as normalization factor $(1 \times \mathrm{RQ}$ for each miR). Parathyroid adenoma samples were highly heterogeneous regarding miR expression levels (Fig. 2). miR-296, miR-222, and miR-503 expression levels in parathyroid adenomas were significantly different from that of carcinoma samples, with miR-296 being down-regulated in carcinomas with respect to adenomas and the other two miRs being over-expressed in PaCs. By contrast, miR-139 levels were similar in parathyroid adenomas and carcinomas, and miR-139 was omitted from global 'miR score' computing. We gave the same weight to all factors and we plotted all the samples' categories according to these score units without generating a threshold value (Fig. 3A). The miR score discriminated both normal samples and adenomas from $\mathrm{PaCs}$ $(P<0.01$ and $P<0.05$ respectively; Kruskal-Wallis test; Fig. 3A).

\section{miR-296, miR-222, and miR-503 target genes expression in human parathyroid tissues}

We investigated HGS, p27/Kip1, and cyclin D1 at mRNA and protein levels, as putative targets of miR-296, miR-222, and miR-503 respectively. At mRNA level, significantly increased HGS mRNA levels were detected in both parathyroid adenomas and carcinomas samples compared with normal specimens (data not shown). Moreover, HGS mRNA expression levels were inversely correlated to miR-296 levels in parathyroid tissues $(r=-0.360$, $P=0.049$; Fig. 3B). p27/Kip1 and cyclin D1 mRNAs were relatively stable across class of samples (data not shown). In regards of targets protein expression, a dramatic increase in HGS staining could be observed in $\mathrm{PaCs}$ compared with adenomatous and normal glands (Fig. 4, upper panels). On the contrary, p27/Kip1 nuclear immunoreactivity was decreased in parathyroid adenomas and lost in neoplastic lesions (Fig. 4, lower panels). Cyclin D1 was expressed at low levels in normal and displayed heterogeneous immunoreactivity in parathyroid adenoma and carcinoma samples (data not shown). 

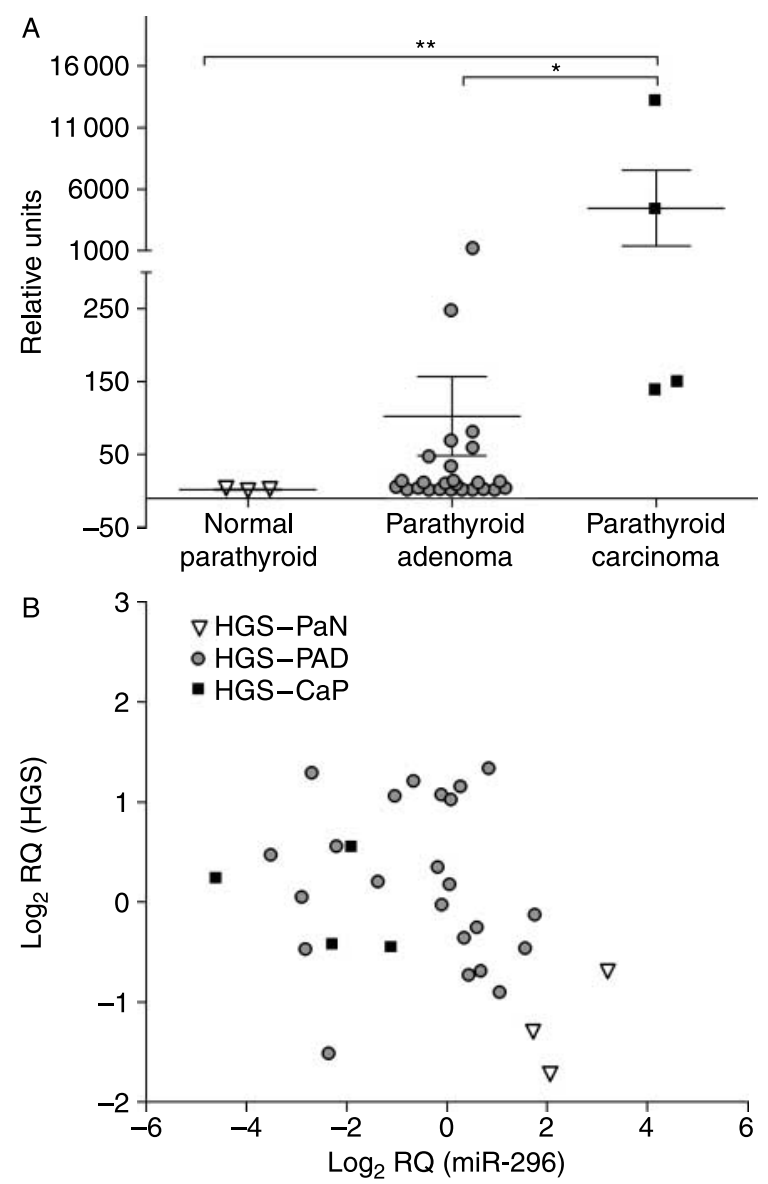

Figure 3 (A) A global 'miR score' was computed on the base of the miR-296, miR-222, and miR-503 expression levels (see Materials and methods section). The same weight was given to all factors, and all the samples' categories were plotted according to these score units without generating a threshold value. The 'miR score' clearly discriminated both normal samples and adenomas from parathyroid carcinomas ( ${ }^{\star *} P<0.01$ and ${ }^{*} P<0.05$ respectively; Kruskal-Wallis test). (B) Correlation between miR-296 expression levels and of its target HGS mRNA levels in normal, adenomatous, and carcinomatous parathyroid tissues $(r=-0.360, P=0.049)$.

\section{Discussion}

$\mathrm{PaC}$ is an aggressive disease with a propensity for recurrences. It is characterized by capsular, vascular, and soft tissue invasions. Recurrence is associated with poor outcome. Little is known about the genetics of $\mathrm{PaC}$, though recently the involvement of parafibromin, the protein product of the CDC73/HRPT2 gene, has been identified. Previous CGH analysis identified chromosomal imbalances with frequent loss and gain of regions in parathyroid cancers (Kytölä et al. 2000). Chromosomal imbalances have been recognized as a mechanism able to alter the expression of miRs. To our knowledge, miRs expression has not been investigated in human parathyroid tissues so far. Indeed, there are several limitations that prevented molecular genetic analysis of these carcinomas in large scale. First, $\mathrm{PaCs}$ are a rare disease with an estimated incidence of 5.7 per 10000000 population (Lee et al. 2007). Secondly, patients with $\mathrm{PaCs}$ are severely hypercalcemic, and the unaffected parathyroids, if available, cannot be used as control since it is known that calcium modulates gene expression (Brown \& MacLeod 2001). Thirdly, PaNs are of difficult availability for ethical reasons; in the present study, normal tissues were from parathyroid glands incidentally removed during surgery for thyroid disease because of their intrathyroidal location. To overcome, at least in part, the limitations due to the low number of pathological and normal samples, in this study we chose to analyze the data setting the cutoff for significance at a high-FC.

With these limitations, we first investigated the miR profiling in $\mathrm{PaCs}$ by low-density miR array based on qPCR technology. Real-Time PCR platform has the generally accepted advantage over microarray technologies to be more accurate and sensitive for quantification of expression data (Schramm et al. 2007), and it is the most used tool to validate gene expression results from array-based screening even in miR investigations (Ambs et al. 2008, Schepeler et al. 2008).

We found that numerous miRs were aberrantly expressed in human PaCs compared with PaN tissues. The overall miR expression could clearly separate normal versus cancer tissues.

We further identified 17 miRs whose expression was significantly deregulated in $\mathrm{PaCs}, 14 \mathrm{miRs}$ being under-expressed and 3 being over-expressed in tumors compared with normal glands. miR genes are frequently located in chromosomal regions characterized by non-random aberrations in human cancers, suggesting that resident miRs expression might be affected by these genetic abnormalities (Calin et al. 2004b). Conversely, none of the 14 down-expressed miRs mapped at locus 1q25-q32, suggesting that loss of heterozygosity at this locus, that occurred in our tumor samples as well as in more than $50 \%$ of familial and sporadic PaCs (Shattuk et al. 2003), does not account for miRs under-expression. Moreover, when considering miR down-regulation, it is worth noting that parafibromin is a component of the human RNA polymerase II-associated factor complex (Rozenblatt-Rosen et al. 2005, Yart et al. 2005), and it has been demonstrated to inhibit the WNT/ $\beta$-catenin/ Tcf/Lef pathway. Accordingly, miRs might be targets of parafibromin modulated $\beta$-catenin transcriptional 

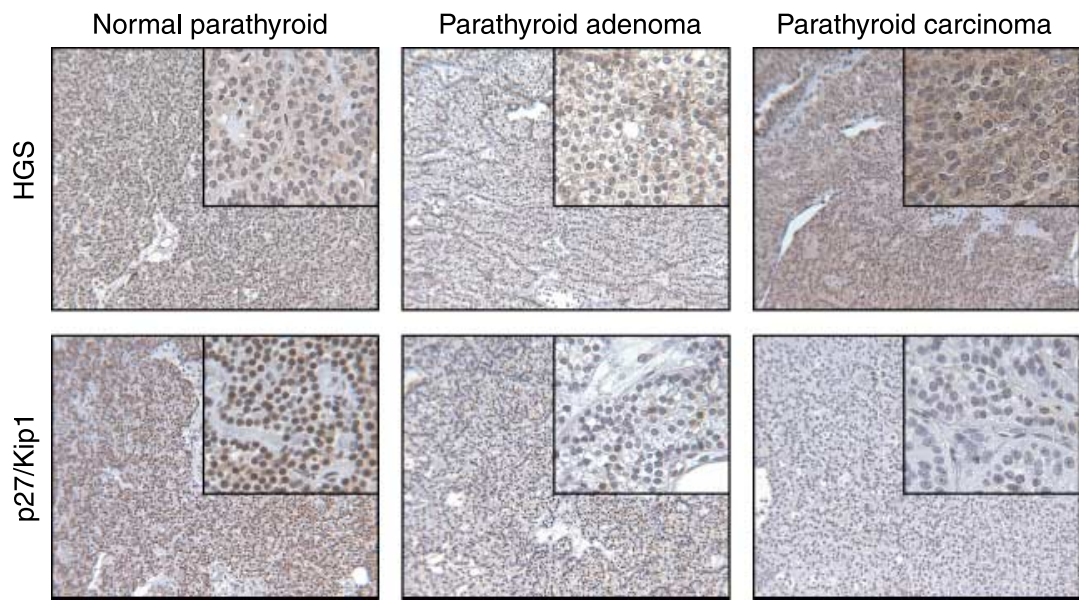

Figure 4 Putative miR-296 and miR-222 target analysis. Protein expression levels of hepatocyte growth factor receptor-regulated tyrosine kinase substrate (HGS) and p27/Kip1 in normal, adenomatous, and carcinomatous parathyroid samples were investigated by immunohistochemistry (original magnification $\times 100$ and $\times 250$ for inserts). Representative immunostaining for HGS (upper line): the HGS expression was low (score $0-1$ ) in normal and adenomatous parathyroid glands, while carcinomas showed an intense positivity (score 3). Conversely, nuclear p27 staining (lower line) was positive in normal parathyroids (score 3) and decreased in tumoral samples (score 1 and 0 ).

activity, whose deregulation has been described in parathyroid tumors (Björklund et al. 2007a,b).

Considering thyroid cancer as a model of endocrine malignancy, this peculiar miR signature set $\mathrm{PaCs}$ between papillary thyroid cancers that are characterized by several up-regulated miRs and few down-regulated miRs with a very low-FC (He et al. 2005, Pallante et al. 2006) and anaplastic thyroid cancer, where miRs are constantly down-regulated (Visone et al. 2007a).

Despite the small sample size, we identified four miRs (miR-296, miR-139, miR-222, and miR-503) that were significantly different between tumoral and $\mathrm{PaN}$ gland with a null FDR. miR-222 (Xp11.3) and miR-503 (Xq26.3) were over-expressed, and the remaining two, miR-296 (20q13.3) and miR-139 (11q13.4), were under-represented, suggesting that they may potentially act as oncogenes or tumor suppressor genes in parathyroid neoplasia respectively.

Of the two up-regulated genes, miR-222 is clustered $(<10 \mathrm{~kb})$ with miR-221. miR-221 has been found to be over-expressed in human thyroid papillary carcinomas together with miR-222. Over-expression of miR-221 has been suggested to be a premalignant change in papillary thyroid cancers (He et al. 2005) as it was found up-regulated both in papillary thyroid cancer and in the unaffected surrounding thyroid tissue. Recent studies have showed that these miRs are implicated in the control of cell cycle progression (Visone et al. 2007b, Medina et al. 2008). In particular, both miR-221 and miR-222 directly target the $3^{\prime}$-untranslated regions of the cyclin-dependent kinase inhibitors p27 and p57 and reduce reporter gene expression as well as protein levels. Interestingly, p27 has been found to be down-regulated in parathyroid tumors (Buchwald et al. 2004).

As far as miR-503 was concerned, the most used internet-based algorithms, TargetScan, PicTar and miRanda, identified genes involved in the parathyroid cell pathophysiology, such as CCDN1, encoding for the cyclin D1 protein, CaSR, encoding for the calcium sensing receptor protein, and $P T H$ among the potentially regulated genes by miR-503.

Of the two under-represented miRs, miR-139 is located at chromosome $11 \mathrm{q} 13$, a fragile region lost in multiple endocrine neoplasia type 1 (MEN1; OMIN \#131100) that is often deleted in PaCs. Finally, miR-296 is poorly conserved and maps to chromosome 20q13.3, near GNAS and GNAS3_HUMAN (encoding for NESP55) loci. Interestingly, the down-regulated miR-296 seems to be restricted to PaCs as it was not reported in other malignancies so far. Very recently, the mouse homolog mir-296 has been reported to be involved in embryonic stem cell differentiation; in particular, abolishing mir-296 activity delays differentiation of mouse embryonic stem cells (Tay et al. 2008).

The extension to a set of sporadic parathyroid adenomas of the analysis of the significant varied miRs between normal and carcinomatous parathyroid tissues showed highly variable pattern of expression. Single miR expression levels could not discriminate between the three classes of specimens. A global score obtained considering RQs of the three most different miRs (miR-222, miR-296, and miR-503) significantly 
discriminated parathyroid adenoma samples from carcinomas, as well as PaNs from neoplastic specimens. According to this score, only 2 adenoma specimens out of the 26 analyzed (7\%) were misclassified, as their score was comparable to that of $\mathrm{PaC}$ group. The use of genes-score or gene-ratios is a relative new strategy for the identification of patients with different prognosis or disease outcome (Gordon et al. 2003, Paik et al. 2004, Stamatopoulos et al. 2009). This observation implies that not single gene but rather small gene-sets could be useful prognostic or predictive factor even when a highly heterogeneous sample population, as parathyroid adenomas, is investigated.

In the attempt to provide functional data supporting the relevance of the present findings, potential miR-296, miR-222, and miR-503 target genes were investigated. Unfortunately, in vitro culture of tumorderived human parathyroid cells is extremely limited and hardly suitable for transfection techniques. Therefore, experiments addressed to analyze the candidate target genes expression were carried out in parathyroid tissues. Recently, HGS, which has been found highly expressed in a number of human cancers (Rayala et al. 2006, Toyoshima et al. 2007), has been reported as a target gene of the miR-296 inhibitory action in primary brain tumor endothelial cells (Würdinger et al. 2008). Accordingly, both PaCs and adenomas characterized by low miR-296 expression levels showed HGS mRNA levels higher than those observed in $\mathrm{PaN}$ tissue. Most importantly, HGS immunoreactivity was strongly increased in PaCs compared with both adenomas and normal tissues. In HeLa cells, HGS over-expression was associated with down-regulation of E-cadherin and increased $\beta$-catenin signaling (Toyoshima et al. 2007). The loss of E-cadherin leads to the nuclear translocation of $\beta$-catenin, which affects two critical cancer promoting processes, i.e. invasion and metastasis, through activation of the Tcf/Lef transcription factor and subsequent activation of growth-promoting genes, such as cyclin Dl and $c-M y c$. The involvement of HGS in the Wnt pathway, which is often deregulated in parathyroid tumors, let us to speculate that miR-296-modulated HGS might be involved in parathyroid cell carcinogenesis.

The cyclin-dependent kinase inhibitor p27/Kip1 has been demonstrated to be a miR-222 target in many experimental systems and in endocrine tumors (Visone et al. 2007b). We therefore evaluated if the higher miR-222 expression detected in PaCs reflected a deregulation in p27/Kip1 expression. Immunohistochemical evaluation of parathyroid tissues showed a progressive decrease in protein staining in adenoma lesions compared with normal glands. Moreover, this cell-cycle inhibitor was almost completely lost in PaCs. These findings strongly suggest that HGS and p27/Kip1 could be targets of miR-296 and miR-222 respectively, in parathyroid pathology. As far as cyclin D1 was concerned, it has been recently demonstrated to be the target of miR-503 (Jiang et al. 2009). In accordance with previous studies reporting over-expression of cyclin D1 in parathyroid tumors (His et al. 1996, Vasef et al. 1999), we found high levels of cyclin D1 in $\mathrm{PaCs}$ and a subset of adenomas. Taking into account that miR-503 was over-expressed in the present series, these data seem to exclude miR-503 as a main modulator of cyclin D1 expression in parathyroid cells.

In conclusion, these results suggest the existence of an altered miR expression pattern in $\mathrm{PaCs}$ together with a potential role of miR-296 as novel oncosuppressor gene in these neoplasia. Moreover, this miR signature might represent a combined multi-markers tool for PaCs discrimination. Finally, it is tempting to speculate that further understanding of function and regulation of these miRs and their target genes might provide the basis for identifying novel diagnostic and therapeutic strategies for this rare disease that continues to be a challenge in the clinical setting and still needs effective treatment modalities.

\section{Supplementary data}

This is linked to the online version of the paper at http://dx. doi.org/10.1677/ERC-09-0134.

\section{Declaration of interest}

The authors declare that there is no conflict of interest that could be perceived as prejudicing the impartiality of the research reported.

\section{Funding}

This work was supported by Istituto Superiore di Sanità 'ITALIA-USA Program 2007 - Malattie Rare' grant no. 8900000 and by Ministero della Salute of Italy 'Progetto Oncologico 2006' (RF06ED01).

\section{References}

Ambs S, Prueitt RL, Yi M, Hudson RS, Howe TM, Petrocca F, Wallace TA, Liu CG, Volinia S, Calin GA et al. 2008 Genomic profiling of microRNA and messenger RNA reveals deregulated microRNA expression in prostate cancer. Cancer Research 68 6162-6170.

Björklund P, Akerström G \& Westin G 2007a Accumulation of nonphosphorylated beta-catenin and c-myc in primary 
and uremic secondary hyperparathyroid tumors. Journal of Clinical Endocrinology and Metabolism 92 338-344.

Björklund P, Akerström G \& Westin G 2007b An LRP5 receptor with internal deletion in hyperparathyroid tumors with implications for deregulated WNT/beta-catenin signalling. PLoS Medicine 4 e 328.

Bondenson L, Grimelius L, DeLellis RA, Lloyd R, Akerstrom G, Larsson C, Arnold A, Eng C, Shane E \& Bilezikian JP 2004 Parathyroid carcinoma. In Pathology and Genetics. Tumors of Endocrine Organs. WHO Classification of Tumors, pp 128-132. Eds RA DeLellis, RV Lloyd, PU Heitz \& C Eng. Lyon: IARC Press.

Brown EM \& MacLeod RJ 2001 Extracellular calcium sensing and extracellular calcium signaling. Physiological Reviews 81 239-297.

Buchwald PC, Akerström G \& Westin G 2004 Reduced p18INK4c, p21CIP1/WAF1 and p27KIP1 mRNA levels in tumors of primary and secondary hyperparathyroidism. Clinical Endocrinology 60 389-393.

Calin GA, Dumitru CD, Shimizu M, Bichi R, Zupo S, Noch E, Aldler H, Rattan S, Keating M, Rai K et al. 2002 Frequent deletions and down-regulation of micro-RNA genes miR15 and miR16 at 13q14 in chronic lymphocytic leukemia. PNAS 99 15524-15529.

Calin GA, Liu CG, Sevignani C, Ferracin M, Felli N, Dumitru CD, Shimizu M, Cimmino A, Zupo S, Dono M et al. 2004a MicroRNA profiling reveals distinct signatures in B cell chronic lymphocytic leukemias. PNAS 101 11755-11760.

Calin GA, Sevignani C, Dumitru CD, Hyslop T, Noch E, Yendamuri S, Shimizu M, Rattan S, Bullrich F, Negrini M et al. 2004b Human microRNA genes are frequently located at fragile sites and genomic regions involved in cancers. PNAS 101 2999-3004.

Carpten JD, Robbins C, Villablanca A, Forsberg L, Presciuttini S, Bailey-Wilson J, Simonds WF, Gillanders EM, Kennedy AM, Chen JD et al. 2002 HRPT2, encoding parafibromin, is mutated in hyperparathyroidism-jaw tumor syndrome. Nature Genetics 32 676-680.

Cetani F, Ambrogini E, Viacava P, Pardi E, Fanelli G, Naccarato AG, Borsari S, Lemmi M, Berti P, Miccoli P et al. 2007 Should parafibromin staining replace HRPT2 gene analysis as an additional tool for histologic diagnosis of parathyroid carcinoma? European Journal of Endocrinology 156 547-554.

Croce CM \& Calin GA 2005 miRNAs, cancer, and stem cell division. Cell 122 6-7.

Doench JG \& Sharp PA 2004 Specificity of microRNA target selection in translational repression. Genes and Development 18 504-511.

Esquela-Kerscher A \& Slack FJ 2006 Oncomirs - microRNA with a role in cancer. Nature Reviews Cancer 6 259-269.

Gill AJ, Clarkson A, Gimm O, Keil J, Dralle H, Howell VM \& Marsh DJ 2006 Loss of nuclear expression of parafibromin distinguishes parathyroid carcinomas and hyperparathyroidism-jaw tumor (HPT-JT) syndrome-related adenomas from sporadic parathyroid adenomas and hyperplasias. American Journal of Surgical Pathology 30 1140-1149.

Gordon GJ, Jensen RV, Hsiao LL, Gullans SR, Blumenstock JE, Richards WG, Jaklitsch MT, Sugarbaker DJ \& Bueno R 2003 Using gene expression ratios to predict outcome among patients with mesothelioma. Journal of the National Cancer Institute 95 598-605.

Griffiths-Jones S, Saini HK, van Dongen S \& Enright AJ 2008 miRBase: tools for microRNA genomics. Nucleic Acids Research 36 D154-D158.

Guarnieri V, Scillitani A, Muscarella LA, Battista C, Bonfitto N, Bisceglia M, Minisola S, Mascia ML, D’Agruma L \& Cole DEC 2006 Diagnosis of parathyroid tumors in familial isolated hyperparathyroidism with HRPT2 mutation: implications for cancer surveillance.

Journal of Clinical Endocrinology and Metabolism 91 2827-2832.

Guarnieri V, Bisceglia M, Bonfitto N, Cetani F, Marcocci C, Minisola S, Battista C, Cole DE \& Scillitani A 2008 Re: familial hyperparathyroidism: surgical outcome after 30 years of follow-up in three families with germline HRPT2 mutations. Surgery 144 839-840.

He H, Jazdzewski K, Li W, Liyanarachchi S, Nagy R, Volinia S, Calin GA, Liu C-G, Franssila K, Suster S et al. 2005 The role of microRNA genes in papillary thyroid carcinoma. PNAS 102 19075-19080.

His ED, Zukerberg LR, Yang WI \& Arnold A 1996 CyclinD1/PRAD1 expression in parathyroid adenomas: an immunohistochemical study. Journal of Clinical Endocrinology and Metabolism 81 1736-1739.

Howell V, Haven C, Kahnoski K, Khoo SK, Petillo D, Chen J, Fleuren GJ, Robinson BG, Delbridge LW, Philips J et al. 2003 HRPT2 mutations are associated with malignancy in sporadic parathyroid tumors. Journal of Medical Genetics 40 657-663.

Iorio MV, Ferracin M, Liu CG, Veronese A, Spizzo R, Sabbioni S, Magri E, Pedriali M, Fabbri M, Campiglio M et al. 2005 MicroRNA gene expression deregulation in human breast cancer. Cancer Research 65 7065-7070.

Jiang Q, Feng MG \& Mo YY 2009 Systematic validation of predicted microRNAs for cyclin D1. BMC Cancer 9194.

Juhlin CC, Villablanca A, Sandelin K, Haglund F, Nordenström J, Forsberg L, Brämström R, Obara T, Arnold A, Larsson C et al. 2007 Parafibromin immunoreactivity: its use as an additional diagnostic marker for parathyroid tumor classification. Endocrine-Related Cancer 14 501-512.

Kytölä S, Farnebo F, Obara T, Isola J, Grimelius L, Farnebo O, Sandelin K \& Larsson C 2000 Patterns of chromosomal imbalances in parathyroid carcinomas. American Journal of Pathology 157 579-586.

Lee PK, Jarosek SL, Virnig BA, Evasovich M \& Tuttle TM 2007 Trends in the incidence and treatment of parathyroid cancer in the United States. Cancer 109 1736-1741. 
Lu J, Getz G, Miska EA, Alvarez-Saavedra E, Lamb J, Peck D, Sweet-Cordero A, Ebert BL, Mak RH, Ferrando AA et al. 2005 MicroRNA expression profiles classify human cancers. Nature 435 834-838.

Marx SJ 2000 Hyperparathyroid and hypoparathyroid disorders. New England Journal of Medicine 343 1863-1875.

Medina R, Zaidi SK, Liiu CG, Stein JL, van Wijnen AJ, Croce CM \& Stein GS 2008 MicroRNAs 221 and 222 bypass quiescence and compromise cell survival. Cancer Research 68 2773-2780.

Nikiforova MN, Tseng GC, Steward D, Diorio D \& Nikiforov YE 2008 MicroRNA expression profiling of thyroid tumors: biological significance and diagnostic utility. Journal of Clinical Endocrinology and Metabolism 93 1600-1608.

Paik S, Shak S, Tang G, Kim C, Baker J, Cronin M, Baehner FL, Walker MG, Watson D, Park T et al. 2004 A multigene assay to predict recurrence of tamoxifentreated, node-negative breast cancer. New England Journal of Medicine 351 2817-2826.

Pallante P, Visone R, Ferracin M, Ferraro A, Berlingieri MT, Troncone G, Chiappetta G, Liu CG, Santoro M, Negrini M et al. 2006 MicroRNA deregulation in human thyroid papillary carcinomas. Endocrine-Related Cancer 13497-508.

Rayala SK, den Hollander P, Balasenthil S, Molli PR, Bean AJ, Vadlamudi RK, Wang R-A \& Kumar R 2006 Hepatocyte growth factor-regulated tyrosine kinase substrate (HRS) interacts with PELP1 and activates MAPK. Journal of Biological Chemistry 281 4395-4403.

Rozenblatt-Rosen O, Hughes CM, Nannepaga SJ, Shanmungam KS, Copeland TD, Guszczynski T, Resau JH \& Meyerson M 2005 The parafibromin tumor suppressor protein is part of a human Paf1 complex. Molecular and Cellular Biology 25 612-620.

Schepeler T, Reinert JT, Ostenfeld MS, Christensen LL, Silahtaroglu AN, Dyrskjøt L, Wiuf C, Sørensen FJ, Kruhøffer M, Laurberg S et al. 2008 Diagnostic and prognostic microRNAs in stage II colon cancer. Cancer Research 68 6416-6424.

Schickel R, Boyerinas B, Park SM \& Peter ME 2008 MicroRNAs: key players in the immune system, differentiation, tumorigenesis and cell death. Oncogene 27 5959-5974.

Schramm A, Vandesompele J, Schulte JH, Dreesmann S, Kaderali L, Brors B, Eils R, Speleman F \& Eggert A 2007 Translating expression profiling into a clinically feasible test to predict neuroblastoma outcome. Clinical Cancer Research 13 1459-1465.

Shattuk TM, Välimäki S, Obara T, Gaz RD, Clark OH, Shoback D, Wierman ME, Tojo K, Robbins CM, Carpten JD et al. 2003 Somatic and germline mutations of the HRPT2 gene in sporadic parathyroid carcinomas. New England Journal of Medicine 349 1722-1729.
Stamatopoulos B, Meuleman N, Haibe-Kains B, Saussoy P, Van den Neste E, Michaux L, Heimann P, Martiat P, Bron D \& Lagneaux L 2009 MicroRNA-29c and microRNA223 downregulation has in vivo significance in chronic lymphocytic leukemia and improves disease risk stratification. Blood 113 5237-5245.

Takamizawa J, Konishi H, Yanagisawa K, Tomida S, Osada H, Endoh H, Harano T, Yatabe Y, Nagino M, Nimura Y et al. 2004 Reduced expression of the let-7 micro-RNAs in human lung cancers in association with shortened post-operative survival. Cancer Research 64 3753-3756.

Tay Y, Zhang J, Thomson AM, Lim B \& Rigoutsos I 2008 MicroRNAs to Nanog, Oct4 and Sox 2 coding regions modulate embryonic stem cell differentiation. Nature $\mathbf{4 5 5}$ 1124-1128.

Toyoshima M, Tanaka N, Aoki J, Tanaka Y, Murata K, Kyuuma M, Kobayashi H, Ishii N, Yaegashi N \& Sugamura K 2007 Inhibition of tumor growth and metastasis by depletion of vescicular sorting protein Hrs: its regulatory role on E-cadherin and beta-catenin. Cancer Research 67 5162-5171.

Vasef MA, Brynes RK, Sturm M, Bromley C \& Robinson RA 1999 Expression of cyclin D1 in parathyroid carcinomas, adenomas, and hyperplasias: a paraffin immunohistochemical study. Modern Pathology 12 412-416.

Visone R, Pallante P, Vecchione A, Cirombella R, Ferracin M, Ferraro A, Volinia S, Coluzzi S, Leone V, Borbone E et al. 2007 a Specific microRNAs are downregulated in human thyroid anaplastic carcinomas. Oncogene $\mathbf{2 6}$ 7590-7595.

Visone R, Russo L, Pallante P, De Martino I, Ferraro A, Leone V, Borbone E, Petrocca F, Alder H, Croce CM et al. $2007 b$ MicroRNAs (miR)-221 and miR-222, both overexpressed in human thyroid papillary carcinomas, regulate p27kip1 protein levels and cell cycle.

Endocrine-Related Cancer 14 791-798.

Weber F, Teresi RE, Broelsch CE, Frilling A \& Eng C 2006 A limited set of human microRNA is deregulated in follicular thyroid carcinoma. Journal of Clinical Endocrinology and Metabolism 91 3584-3591.

Würdinger T, Tannous BA, Saydam O, Skog J, Grau S, Soutschek J, Weissleder R, Breakefield XO \& Krichevsky AM 2008 miR-296 regulates growth factor receptor overexpression in angiogenic endothelial cells. Cancer Cell 14 382-393.

Yart A, Gstaiger M, Wirbelauer C, Pecnik M, Anastasiou D, Hess D \& Krek W 2005 The HRPT2 tumor suppressor gene product parafibromin associates with human PAF1 and RNA polymerase II. Molecular and Cellular Biology 25 5052-5060. 